\title{
Histologia del sistema reproductor masculino de Helobdella hyalina (Hirudinea, Glossiphoniidae) en Argentina
}

\author{
Betina Sandra Gullo
}

\author{
Universidad Nacional de La Plata, Facultad de Ciencias Naturales y Museo (UNLP), Paseo del Bosque s/n 1900, La Plata, \\ Argentina. (bgullo@museo.fcnym.unlp.edu.ar)
}

\begin{abstract}
Histology of the male reproductive system of Helobdella hyalina (Hirudinea, Glossiphoniidae) in Argentina. A detailed preliminary histological analysis of Helobdella hyalina Ringuelet, 1942 male system from Los Talas, Buenos Aires, Argentina is described. Six pairs of testisacs, located between the crop caeca, form the male reproductive system. Each testisac is clothed by the mesotelium. Inside it, the germinal cells are connected to the citophore and develop functional unit called poliplast. The spermatozoa are released into testisacs after the reabsortion of the citophore. Five stages of spermatogenesis are described taking into account the successive maturation stages of germinal cells and the changes in the citophore size. Lining cells and gland cells were found in the seminal vesicle. Five different types of gland cells are placed inside the ejaculatory ducts, as well as two kinds of cells are found in its distal portion: type 1, which produces eosinophilic granular secretion, type 2, with amorphous and slightly eosinophilic. Three distinct gland cells are located in the proximal portion of the duct: type 3, which produces a strongly eosinophilic granular secretion; type 4, with a negative eosinophilic amorphous secretion and type 5, with a basophilic granular secretion. Type 5 gland cells are described for the ducts of this species only.
\end{abstract}

KEYWORDS. Histology, reproductive system, Helobdella.

\section{INTRODUCCIÓN}

Helobdella hyalina Ringuelet, 1942 es una sanguijuela muy frecuente en las asociaciones de invertebrados del área rioplatense, Argentina. Sus poblaciones se hallan en diversos ambientes tanto lóticos como lénticos. La anatomía del sistema reproductor de esta especie fue descripta por Ringuelet (1942). Varios autores han estudiado en detalle la histología del sistema reproductor en hirudíneos Glossiphoniidae: DAMAs (1964, 1965, 1966, 1968a, b, 1977) en Glossiphonia complanata (Linnaeus, 1758), Martínez Alós \& García Corrales (1988) en Helobdella stagnalis (L., 1758) y FERNÁNDEZ et al. (1992) en H. triserialis (Blanchard, 1849). En Argentina, Gullo (1994, 1995, 1999) efectuó estudios microanatómicos del sistema reproductor femenino y masculino de $H$. triserialis y del sistema reproductor femenino de $H$. hyalina.

El objeto es efectuar un estudio histológico de las gónadas, vías de evacuación masculinas y espermatogénesis de $H$. hyalina.

\section{MATERIAL Y MÉTODOS}

Se efectuaron muestreos mensuales (desde febrero a septiembre de 1997) en un canal de riego situado (3453' S y $57^{\circ} 50$ ' W) en la localidad de Los Talas, Provincia de Buenos Aires, Argentina. El canal se hallaba cubierto por Azolla filiculoides Lamarck, Lemna minuscula Herter, Spirodella intermedia Koch, Wolffiella oblonga Hegelmaier y Ceratophyllum demersum Linnaeus. En cada muestreo se obtuvieron seis muestras de la vegetación flotante utilizando un muestreador de $900 \mathrm{~cm}^{2}$ de área y red de $0,5 \mathrm{~mm}$ de abertura de malla. En el laboratorio se efectuó el lavado de la vegetación empleando un tamiz de $200 \mu \mathrm{m}$. Se obtuvo el peso húmedo de los ejemplares empleando una balanza analítica con una precisión de $0,1 \mathrm{mg}$.

Para el examen microanatómico fueron procesados la totalidad de los especimenes censados $(n=116)$ comprendiendo un amplio espectro de pesos (0,2 a $3 \mathrm{mg}$ ). Se empleó Carnoy 6:3:1 como líquido fijador. La inclusión se realizó in toto empleando parafina y se efectuaron secciones histológicas seriadas de $7 \mu \mathrm{m}$. Para la coloración se utilizó Hematoxilina de Meyer y Eosina y el Azan de Heidenhein (GABE, 1968).

La talla nuclear y citoplasmática se obtuvo considerando el diámetro de las células cuya sección pasa por el núcleo. En las células glandulares sólo se consideró la talla nuclear debido a la dificultad para establecer los límites de las mismas. El examen histológico se efectuó con un microscopio binocular con equipo fotográfico automático. El material estudiado se encuentra depositado en la Colección de la División Zoología Invertebrados del Museo de La Plata, Argentina ( $n^{\circ}$ 6083).

\section{RESULTADOS}

Helobdella hyalina presenta seis pares de testisacos localizados entre los ciegos gástricos extendiéndose desde el somito XIII/ XIV hasta el XVIII/ XIX. Los testisacos se hallan revestidos por un epitelio simple que se apoya sobre la membrana basal. Este epitelio esta formado por dos tipos de células de revestimiento: células planas mesoteliales y células cúbicas. Las células mesoteliales son planas y forman una capa continua. Presentan citoplasma acidófilo y el núcleo es oval. La talla nuclear es 11,6 $\pm 0,4 \mu \mathrm{m} \times 3 \pm 0,3 \mu \mathrm{m}, \mathrm{n}=10$ (fig. 1). Las células cúbicas poseen citoplasma acidófilo (talla: $6,37 \pm$ $1,26 \mu \mathrm{m}, \mathrm{n}=10$ ) y un núcleo esférico con una talla de $3 \pm$ $0,3 \mu \mathrm{m}, \mathrm{n}=10$. Estas últimas se hacen más numerosas $\mathrm{y}$ evidentes a medida que progresa la espermatogénesis y se dividen por mitosis para formar fagocitos. Los fagocitos 
presentan una talla nuclear de 3,98 $\pm 0,61 \mu \mathrm{m}$ y citoplasmática de $8,54 \pm 0,32 \mu \mathrm{m}, \mathrm{n}=10$ (fig. 2).

La espermatogénesis se inicia con la proliferación de espermatogonias originadas a partir del epitelio germinal del testisaco. Cada espermatogonia se divide mitóticamente originando un clon o grupo isogénico. Las espermatogonias presentan un núcleo esférico y su talla nuclear es de 4,54 $\mu \mathrm{m} \pm 0,59(\mathrm{n}=25)$. La cromatina es de disposición perinuclear adosada a la carioteca (fig. 3 ). Los espermatocitos en profase meiótica presentan una talla nuclear de $4,25 \mu \mathrm{m} \pm 0,84(\mathrm{n}=25)$ y tienen la cromatina condensada (fig. 4). La talla nuclear de las espermátides es de $1,15 \mu \mathrm{m} \pm 0,18(\mathrm{n}=25)$. En el marco de la espermiohistogénesis el núcleo se alarga adoptando forma elíptica (fig. 5). Los espermatozoides presentan una talla nuclear de 1,06 $\mu \mathrm{m} \pm 0,07(\mathrm{n}=25)$. Se pueden diferenciar tres zonas: una anterior y posterior eosinófila (corresponden al acrosoma y al flagelo respectivamente) y la media basófila que corresponde al núcleo (figs. 6,11 , 17).

La espermatogénesis se dividió en cinco etapas teniendo en cuenta la maduración de los elementos germinales y los cambios en el aspecto y volumen de la región central del poliplasto (citóforo): etapa 1: se caracteriza por la proliferación de elementos goniales. En el interior del testisaco las espermatogonias se dividen mitóticamente (fig. 7), permanecen conectadas unas con otras por largos períodos de tiempo y constituyen
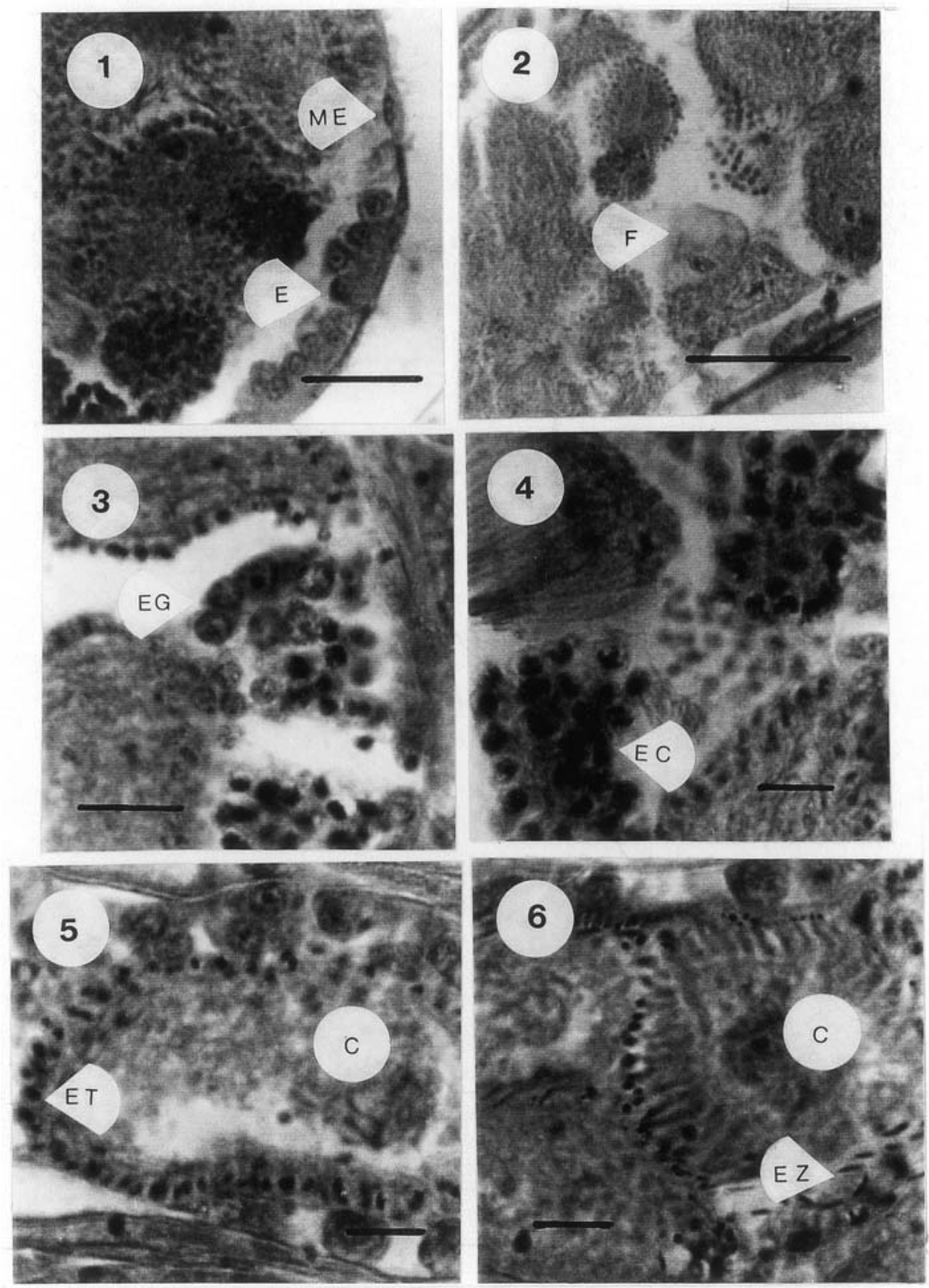

Figs. 1-6. Helobdella hyalina: 1, corte transversal de la pared del testisaco; 2, fagocito en el lumen testicular; 3, espermatogonias; 4, espermatocitos en profase de meiosis; 5, espermátides; 6, espermatozoides (C, citóforo; E, epitelio cúbico; EC, espermatocitos en profase de la primera división meiótica; EG, espermatogonias; ET, espermátides; EZ, espermatozoides; F, fagocito; ME, célula mesotelial). Escalas: $25 \mu \mathrm{m}$, fig. $1 ; 50 \mu \mathrm{m}$, fig. $2 ; 10 \mu \mathrm{m}$, figs. 3-6. 
poliplastos germinales. Estas divisiones no van acompañadas de divisiones citoplásmicas de modo que las espermatogonias quedan unidas a la región central del poliplasto denominada citóforo, que en esta etapa no es muy voluminoso (fig. 8); etapa 2: los espermatocitos se hallan en profase de la primera división meiótica. Presentan un núcleo con condensación cromatínica. El citóforo se torna más granular e incrementa su volumen (figs. 7, 9); etapa 3: se caracteriza por la presencia de espermátides. En el marco de esta etapa la serie germinal culmina con la formación del flagelo. El volumen del citóforo se estabiliza. No se observan procesos autolíticos (fig. 10); etapa 4: finaliza la espermiohistogénesis y los espermatozoides se orientan con sus acrosomas vinculados con el citofóro y su flagelo opuesto a él (fig. 11). El citóforo experimenta un proceso de reabsorción directa (autólisis) (fig. 12) con la liberación de los espermatozoides a la luz del testisaco (fig. 13). Posteriormente los fagocitos reabsorben los remanentes de citóforo (reabsorción reaccional) (fig. 12); etapa 5: con posterioridad a la puesta los nuevos poliplastos germinales formados son reabsorbidos por acción de los fagocitos, de manera que no es posible la restauración gonadal (fig. 14).

Vías de evacuación. La salida de los espermatozoides tiene lugar a través de un embudo testicular que se abre en el canal eferente (figs. 13, 15). Los canales eferentes y deferentes están formados por un epitelio cúbico simple. La vesícula seminal presenta

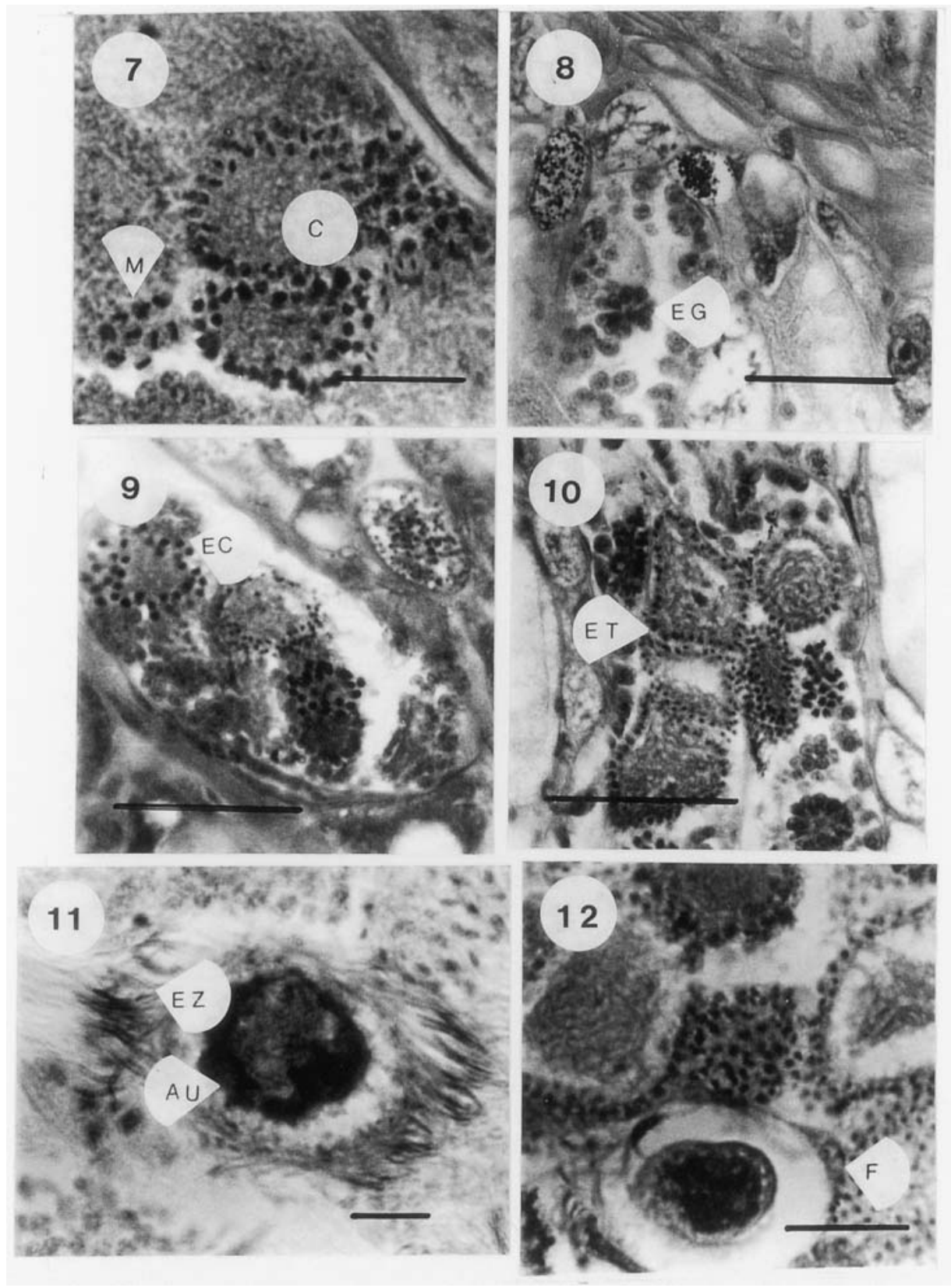

Figs. 7-12. Helobdella hyalina: 7, división mitótica de espermatogonias y espermatocitos; 8, etapa 1 de la espermatogénesis; 9, etapa 2 de la espermatogénesis; 10 , etapa 3; 11, etapa 4 reabsorción directa; 12, etapa 4 reabsorción reaccional (AU, autólisis; C, citóforo; EC, espermatocitos en profase de la primera división meiótica; EG, espermatogonias; ET, espermátides; EZ, espermatozoides; F,

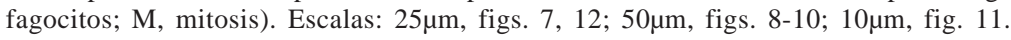


células glandulares y células de revestimiento. Las células glandulares son globosas, com un núcleo esférico (talla nuclear: $6,9 \pm 0,1 \mu \mathrm{m} ; \mathrm{n}=10$ ) y producen una secreción granular eosinófila. Las células de revestimiento son planas; tienen una talla nuclear de $3 \pm 0,3 \mu \mathrm{m} ; \mathrm{n}=10 \mathrm{y}$ alternan con las células glandulares aunque predominan estas últimas (fig. 16). En la luz de la vesícula seminal se observan fascículos de espermatozoides acompañados de células conjuntivas de núcleos esféricos (talla nuclear $3,49 \pm 0,2 \mu \mathrm{m}$; talla citoplasmática $8,75 \pm 0,22 \mu \mathrm{m} ; \mathrm{n}=10$ ) (fig. 17).

El conducto eyaculador presenta un epitelio simple constituido por células planas de revestimiento (talla nuclear 2,6 $\pm 0,21 \mu \mathrm{m} ; \mathrm{n}=10$ ) y células de naturaleza

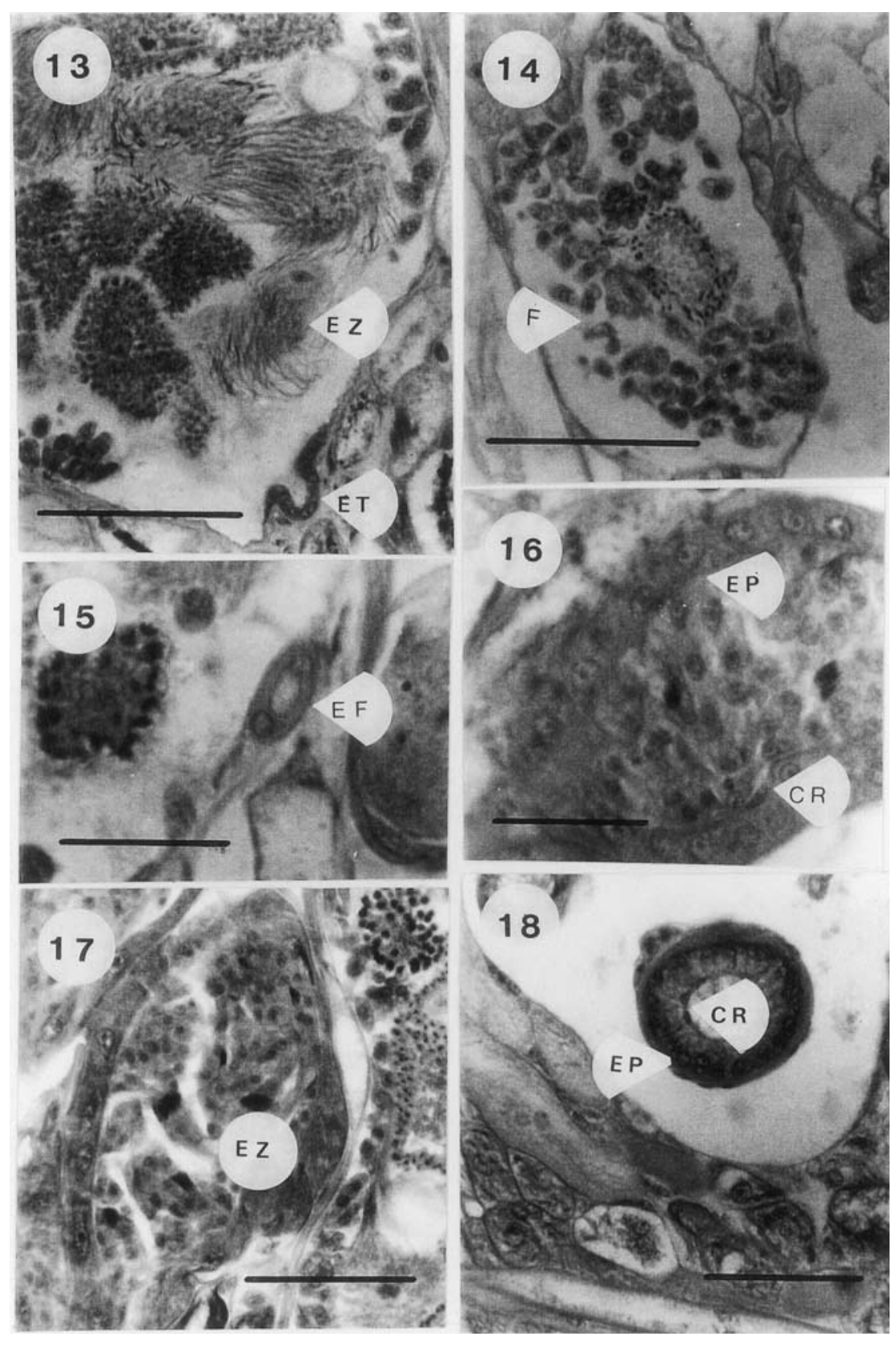

Figs. 13-18. Helobdella hyalina: 13, etapa 4 y embudo testicular; 14, etapa 5; 15, corte transversal del conducto eferente; 16, sección transversal de la vesícula seminal; 17, ídem con espermatozoides en su interior; 18, corte transversal de la región I del conducto eyaculador (CR, células de revestimiento; EF, conducto eferente; EP, epitelio glandular; ET, embudo testicular; EZ, espermatozoides; F, fagocitos). Escalas: $50 \mu \mathrm{m}$, figs. 13, 14, 17, 18; $25 \mu \mathrm{m}$, figs. $15,16$. glandular (fig. 18). En su porción distal (región I) se hallaron dos tipos de células glandulares (tab. I). Las células glandulares tipo 1 son columnares con núcleo esférico (talla nuclear: $6,9 \pm 0,10 \mu \mathrm{m} ; \mathrm{n}=10$ ) y producen gránulos esféricos cuya talla es $1,3 \pm 0,13 \mu \mathrm{m} ; \mathrm{n}=10$. Las células tipo 2 tienen forma oval y núcleo esférico (talla nuclear: 3,5 $\pm 0,24 \mu \mathrm{m} ; \mathrm{n}=10$ ), y producen una secreción amorfa (fig. 19). Los tipos glandulares 1 y 2 se localizan a lo largo de toda la región I del conducto eyaculador. En la región proximal (región II) se han identificado tres tipos celulares (tab. I). Las células glandulares tipo 3 son columnares (talla nuclear 4,9 $\pm 0,09 \mu \mathrm{m} ; \mathrm{n}=10$ ) y su ubicación en el conducto es dorsolateral (fig. 20). La secreción es granular observándose un gradiente en la 
talla de los gránulos con un empaquetamiento de los mismos hacia la desembocadura del conducto, tornándose más esféricos (talla: 1,79 $\pm 0,24 \mu \mathrm{m} ; \mathrm{n}=10$ ) (figs. 22, 23). Intercaladas entre las células tipo 3 se observan células glandulares tipo 5, columnares con núcleo oval (talla: $2,6 \pm 0,21 \mu \mathrm{m} \times 1,75 \pm 0,14 ; \mathrm{n}=10$ ) cuya secreción es granular. Los gránulos son esféricos (talla: $1,3 \pm 0,13 \mu \mathrm{m} ; \mathrm{n}=10$ ) (fig. 20). Las células tipo 4 presentan citoplasma hialino y los núcleos son ovales (talla: 3,5 \pm $0,24 \mu \mathrm{m} \times 1,75 \pm 0,14 \mu \mathrm{m} ; \mathrm{n}=10)$; se localizan en la región ventral del conducto y producen grandes vesículas con secreción amorfa (figs. 21-23).

El atrio genital es una pequeña cavidad tapizada por un epitelio simple, debajo del cual se halla una capa de fibras musculares de disposición circular constituyendo un esfínter (fig. 24).
Tabla I. Tipos glandulares hallados en el conducto eyaculador de Helobdella hyalina y afinidad tintorial de su secreción. Región I: zona distal del conducto eyaculador; región II: zona proximal del conducto eyaculador.

\begin{tabular}{lccc}
\hline Glándulas & A zan de Heidenhain & Hematoxilina y eosina & Secreción \\
\hline Región I & & & \\
Tipo 1 & fuertemente cianófila & eosinófila & granular \\
Tipo 2 & ligeramente cianófila & ligeramente eosinófila & amorfa \\
& & & \\
Región II & & & \\
& & & \\
Tipo 3 & eritrófila (rojo) & fuertemente eosinófila & granular \\
Tipo 4 & cianófila & eosinófila negativa & amorfa \\
Tipo 5 & fuertemente cianófila & basófila & granular \\
\hline
\end{tabular}
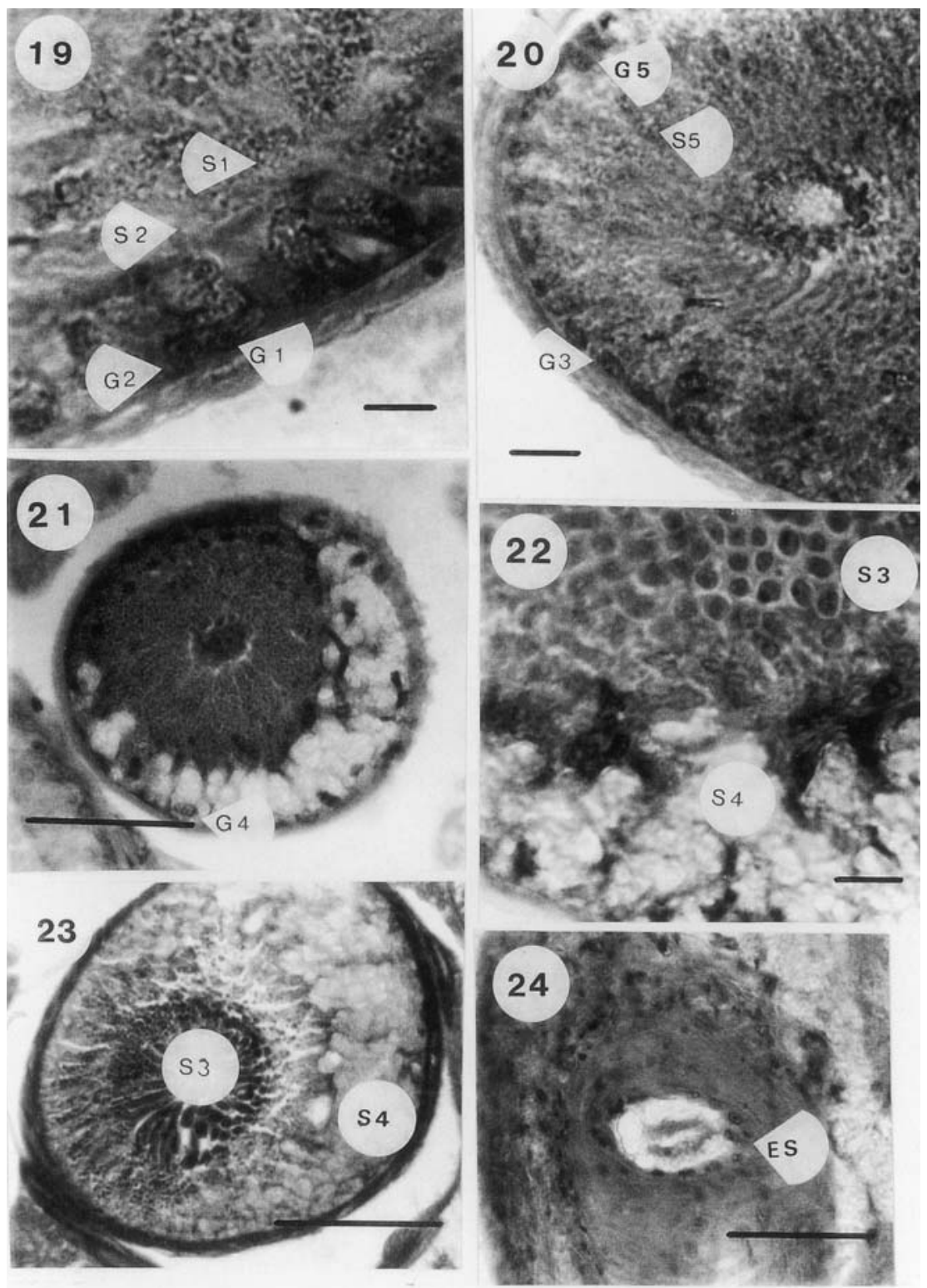

Figs. 19-24. Helobdella hyalina: 19, tipos glandulares de la región I del conducto eyaculador; 20, tipos glandulares de la región II del conducto eyaculador; 21, secreciones de la región II del conducto eyaculador; 22, secreción granular y amorfa de la región II del conducto eyaculador; 23, secreciones de la región II del conducto; 24, atrio genital (ES, esfínter; G1 y G2, tipos glandulares de la región I del conducto; S1 y S2, secreciones de la región I del conducto; G3, G4 y G5, tipos glandulares de la región II; S3, S4 y S5, secreciones de

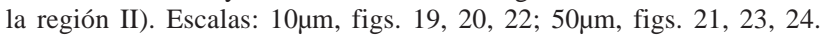




\section{DISCUSIÓN}

En relación al origen de las células germinales, DAMAS (1968b) sugiere que las células ciliadas de los sacos testiculares de Glossiphonia complanata actuan como un verdadero epitelio germinativo, pierden sus cilias, se desprenden de la membrana basal y se transforman en espermatogonias primitivas. VAN DAMME (1974) postula que el origen de las células germinales de Erpobdella octoculata (L., 1758), y en general en todos los erpobdellidos está en el cordón germinal primordial de un individuo joven cuando abandona el capullo. Según Bonnet \& Molinas (1988), las células germinales de Dina lineata (Müller, 1974) se originan del cordón germinal primordial ya que las células cúbico ciliadas que tapizan el epitelio hacen poco probable que puedan originar espermatogonias primitivas. Con la excepción de G. complanata (DAmAs, 1968b), Placobdella costata (Fr. Müller, 1846) (O' DONOVAN \& ABRAHAM, 1987) y H. stagnalis (MARTinez Alós \& García Corrales, 1988) en ninguna otra especie se había descripto la formación de elementos germinales por desdiferenciación de otras células especializadas. En H. hyalina, a semejanza de lo observado en H. triserialis (GuLlo, 1995), no fueron observadas células ciliadas en los sacos testiculares. La presencia de células planas carentes de cilios y espermatogonias en la luz del testisaco en los estadios tempranos de desarrollo, permiten suponer un origen a partir del cordón germinal primordial.

Los cambios en el aspecto y volumen del citóforo observados en $H$. hyalina han sido descriptos en otras especies como G. complanata (DAmas, 1968b), Dina lineata (BonNET \& MolinAs, 1988), H. stagnalis (MARTÍNEZ Alós \& García Corrales, 1988) y H. triserialis (Gullo, 1995) y están vinculados a la maduración de los elementos germinales. A medida que se suceden las divisiones nucleares, el volumen de los núcleos disminuye incrementándose el volumen del citóforo. Según FERNÁNDEZ et al. (1992), el citóforo contiene numerosas organelas y su función es sincronizar la proliferación y diferenciación de los elementos germinales. Con referencia al desarrollo de los elementos germinales de $H$. hyalina, no se ha observado un ciclo anual ni se ha podido distinguir entre espermatogonias de invierno y de verano tal como observara DAmas (1968b), aunque se observaron modificaciones en el citóforo durante la espermatogénesis.

En la región I del ducto eyaculador se halló el tipo 1 que por su forma, ubicación y forma de los gránulos podría compararse con las células glandulares $\mathrm{S}_{1}$ de $H$. triserialis (Gullo, 1995) y a las $\mathrm{C}_{1}$ de H. stagnalis (Martínez Alós \& García Corrales, 1988). El tipo 2 hallado en $H$. hyalina podría compararse con el tipo $\mathrm{C}_{3}$ hallado en $H$. stagnalis y a las $\mathrm{S}_{2}$ de $H$. triserialis. Con referencia a la región II, las células tipo 3 podrían compararse a las células $\mathrm{A}_{1}$ descriptas por MARTíneZ Alós \& García Corrales (1988) y a las células tipo $\mathrm{S}_{3}$ de $H$. triserialis (Gullo, 1995). El gradiente de talla observado en las granulaciones podría vincularse a una progresión evolutiva de la secreción de la porción más proximal a la más distal del conducto como sucede en $H$. triserialis. Las células tipo 4 podrían equipararse a las caliciformes $\mathrm{C}_{4}$ citadas por Martínez Alós \& García

Recebido em agosto de 2002. Aceito em julho de 2003. ISSN 0073-4721
Corrales (1988) y a las células $\mathrm{S}_{4}$ descriptas para $H$. triserialis en tanto las células tipo 5 sólo han sido descriptas para las vías de evacuación de $H$. hyalina. Las secreciones producidas en la región I y II del conducto eyaculador contribuyen a la formación de los espermatóforos como ocurre en otras especies de hirudíneos Rhyncobdellidos (SAWYER, 1986).

Agradecimientos. A la División Zoología Invertebrados de la Facultad de Ciencias Naturales y Museo (UNLP) por facilitarme el equipo fotográfico y a la Dra. María Cristina Damborenea (UNLP) por la lectura crítica del manuscrito.

\section{REFERENCIAS BIBLIOGRÁFICAS}

Bonnet, S. \& Molinas, M. 1988. Anatomía e histología del aparato reproductor de Dina lineata (Müller, 1974) (Hirudinea, Erpobdellidae). Boletín de la Real Sociedad Espanhola de Historia Natural Sección Biologica, Madrid, 84(1-2):7389.

DAMAS, D. 1964. Structure et rôle du rachis ovarien chez Glossiphonia complanata (Hirudinée, Rhyncobdelle). Bulletin de la Société Zoologique de France, Paris, 89(2-3):147-155.

1965. Mode de nutrition des cellules mâles et femelles de Glossiphonia complanata L. (Hirudinée) durant la spermatogenèse et l'ovogenèse. Bulletin de la Société Zoologique de France, Paris, 90:337-338.

1966. Anatomie et histologie des canaux éyaculateurs de Glossiphonia complanata L. (Hirudinée, Rhyncobdelle). Archives de Zoologie Expérimentale et Générale, Paris, 107:325-336.

1968a. Histochimie des canaux éyaculateurs de Glossiphonia complanata L. (Hirudinée, Rhyncobdelle). Annales d'Histochimie, Paris, 13:111-122.

1968b. Les cellules germinales màles de Glossiphonia complanata (Hirudinée, Rhyncobdelle). Origine, evolution et structure. Bulletin de la Société Zoologique de France, Paris, 93:375-385.

1977. Anatomie et évolution de l'appareil génital femmelle de Glossiphonia complanata (Hirudinée, Rhyncobdelle), au cours du cycle annual. Etude histologique et ultrastructurale. Archives de Zoologie Expérimentale et Générale, Paris, 118(1):29-42.

Fernández, J.; Téllez, V. \& Olea, N. 1992. Hirudinea. In: Harrison, F. W. \& Gardiner, S. L. eds. Microscopic anatomy of Invertebrates, New York,Willey-Liss. v.7, p.323-394.

GaBE, M. 1968. Techniques histologiques. Paris, Masson. 1113p.

Gullo, B. S. 1994. Microanatomía de la gónada femenina de Helobdella triserialis (Hirudinea, Glossiphoniidae). Anales de la Sociedad Científica Argentina, Buenos Aires, 224(2):43-55.

1995. Microanatomía de la gónada y vías de evacuación masculinas de Helobdella triserialis (Hirudinea, Glossiphoniidae). Neotropica, La Plata, 41(105, 106):67-75.

1999. Ovogénesis y estructura ovárica de Helobdella hyalina (Hirudinea, Glossiphoniidae) en Los Talas (Pdo de Berisso), Buenos Aires. Neotropica, La Plata, 45(113-114):31-36.

Martínez Alós, S. \& García Corrales, P. 1988. Anatomía e histología del aparato reproductor de Helobdella stagnalis L. (Annelida, Hirudinea, Rhyncobdellida, Glossiphoniidae). Boletín de la Real Sociedad Espanhola de Historia Natural Sección Biologica, Madrid, 84(1-2):15-31.

O' Donovan, P. \& Abraham, M. 1987. Somatic tissue-male germ cells barrier in three hermaphrodite invertebrates: Dugesia biblica (Platyhelminthes), Placobdella costata (Annelida), Levantina hierosolyma (Mollusca). Journal of Morphology, Amsterdam, 192:217-227.

Ringuelet, R. A. 1942. Descripciones preliminares de nuevos hirudíneos argentinos. Notas del Museo de La Plata, Zoologia, La Plata, 7(59):203-214.

SAWYER, R. T. 1986. Leech biology and behaviour. Oxford, Clarendon. $4417 \mathrm{p}$.

VAn Damme, N. 1974. Organogénèses de 1' appareil genital chez la sangsue Erpobdella octoculata L. (Hirudinées; Pharyngobdelle). Archives de Biologie, Paris 85(3):373-397. 